\title{
CpG motif in synthetic ODN primes respiratory burst of olive flounder Paralichthys olivaceus phagocytes and enhances protection against Edwardsiella tarda
}

\author{
Chan Hwei Lee ${ }^{1}$, Hyun Do Jeong ${ }^{1}$, Joon Ki Chung ${ }^{1}$, Hyung Ho Lee ${ }^{2}$, Ki Hong Kim ${ }^{1, *}$ \\ ${ }^{1}$ Department of Aquatic Life Medicine, Pukyong National University, Pusan 608-737, South Korea \\ ${ }^{2}$ Faculty of Food Science and Biotechnology, Pukyong National University, Pusan 608-737, South Korea
}

\begin{abstract}
Effects of synthetic cytidine-phosphate-guanosine (CpG) oligodeoxynucleotide (ODN) on respiratory burst activity of olive flounder (Paralichthys olivaceus) head-kidney phagocytes and on protection against lethal infection with Edwardsiella tarda were investigated. Phagocytes precultured with a CpG ODN showed significantly higher chemiluminescence (CL) responses than phagocytes precultured with guanosine-phosphate-cytidine (GpC) ODN or culture medium alone (control) at all concentrations. Supernatants produced from leucocytes, which were pulsed with CpG ODN, induced significantly higher respiratory burst activity than supernatants produced by GpC ODN or culture medium alone. In an in vivo experiment, respiratory burst activities of the head kidney phagocytes in the groups injected either 0.25 or $0.5 \mu \mathrm{gish}^{-1}$ of CpG ODN were significantly higher than those in the groups injected with GpC ODN or HBSS (control) at 3, 5 and $7 \mathrm{~d}$ after injection. The groups of fish injected with 0.25 or $0.5 \mu \mathrm{g}$ of CpG ODN showed higher survival rates $(83.3 \%)$ than groups treated with GpC ODN (33.3\%) and a control group (8.3\%) after challenge with E. tarda. The present in vitro and in vivo experiments have demonstrated the ability of synthetic CpG ODN to increase phagocyte respiratory burst activity and disease resistance in olive flounder.
\end{abstract}

KEY WORDS: Synthetic CpG ODN · Olive flounder - Respiratory burst · Phagocytes · Disease resistance $\cdot$ Edwardsiella tarda

\section{INTRODUCTION}

The innate immune system of vertebrates recognizes unmethylated cytidine-phosphate-guanosine (CpG) dinucleotides flanked by specific bases in bacterial DNA as a danger signal (Krieg et al. 1995, 2000). Such sequences are approximately 20 times more common in microbial than in mammalian DNA due to differences in the utilization frequency and methylation pattern of $\mathrm{CpG}$ dinucleotides in prokaryotes versus eukaryotes (Bird 1980, 1987). Synthetic oligodeoxynucleotides (ODN) containing CpG motifs (CpG ODN) mimic the activity of bacterial DNA (Yamamoto et al. 1992, Krieg et al. 1995, Ballas et al. 1996, Klinman et al.
1996). A possible molecular mechanism whereby bacterial DNA activates immune cells is revealed with the discovery of Toll-like receptor 9 (TLR9) in mice, a transmembrane receptor capable of recognizing unmethylated CpG oligonucleotides in bacterial DNA. The motifs are internalized into acidified endosomal vesicles (Hemmi et al. 2000), and released to trigger immune stimulation through a signaling cascade that involves the up-regulation of NF- B (Krieg et al. 2000). Antigen presenting cells (APCs) triggered by CpG-ODN up-regulate their expression of co-receptor molecules and secrete a variety of cytokines, including IL-12, IL-6, IL-1 and TNF- (Stacey et al. 1996, Chase et al. 1997, Lipford et al. 1997). 
To date, there is limited information concerning the biological effects of CpG ODN on fish. Kanellos et al. (1999) reported that plasmids co-injected with a recombinant protein potentiated antibody responses to the protein in goldfish Carassius auratus. Recently, Jørgensen et al. (2001a,b) demonstrated that plasmid DNA and synthetic CpG ODN induced production of IFN-like cytokine and IL-1 in Atlantic salmon Salmo salar and rainbow trout Oncorhynchus mykiss leucocytes. Oumouna et al. (2002) demonstrated activation of nonspecific cytotoxic cells of catfish Ictalurus punctatus with synthetic ODN and bacterial genomic DNA. Tassakka \& Sakai (2002) reported that intraperitoneal injection of CpG ODN in carp Cyprinus carpio enhanced the nonspecific immune responses, including phagocytic and nitroblue tetrazolium (NBT) activity in kidney phagocytes and serum lysozyme activity. Meng et al. (2003) observed an increase of respiratory burst activity, acid phosphatase and bactericidal activity of grass carp (Ctenopharyngodon idellus) head-kidney macrophages by in vitro incubation with $\mathrm{CpG}$ ODN. However, the effect of CpG ODN on disease resistance in relation to enhanced non-specific immune responses has not been elucidated so far.

In the present study, we investigated in vitro and in vivo effects of synthetic $\mathrm{CpG}$ ODN on the respiratory burst activity of olive flounder (Paralichthys olivaceus) head-kidney phagocytes. In addition, the effect of intraperitoneal injection of $\mathrm{CpG}$ ODN on the disease resistance was examined by challenge with Edwardsiella tarda.

\section{MATERIALS AND METHODS}

Fish. In in vitro experiments, a total of 30 olive flounder Paralichthys olivaceus weighing 350 to $400 \mathrm{~g}$, obtained from a local fish farm, were kept in $500 \mathrm{l}$ fiberglass tanks containing filtered, aerated sea water at a temperature of $20 \pm 2^{\circ} \mathrm{C}$. Fish were acclimated to these conditions for at least $2 \mathrm{wk}$ before use, and fed commercial flounder pellets. In in vivo experiments, juvenile olive flounder, weighing 35 to $40 \mathrm{~g}$, were obtained from a local fish farm. Fish were stocked into $1050 \mathrm{l}$ aquaria at a density of 12 fish per aquarium, and were acclimated $2 \mathrm{wk}$ prior to initiating the experiment.

ODNs. Nuclease-resistant phosphoro-thioate ODNs were purchased from Bioneer. The sequence of $\mathrm{CpG}$ ODN 1668 was: 5'-TCCATGACGTTCCTGATGCT-3' (CpG motif is underlined). GpC ODN 1720 was synthesized by replacing a CpG dinucleotide in ODN 1668 with a GpC dinucleotide.

Isolation of head-kidney phagocytes. Fish were anaesthetized with tricaine methanesulfonate (MS222;
Sigma). The head kidney was extracted by ventral incision and transferred to L-15 medium (Sigma) supplemented with $2 \%$ foetal calf serum (FCS; Sigma), heparin (10 $\mathrm{U} \mathrm{ml}^{-1}$, Sigma), penicillin $\left(100 \mathrm{\mu g} \mathrm{ml}^{-1}\right.$, Sigma) and streptomycin (100 $\mathrm{U} \mathrm{ml}^{-1}$, Sigma). To get leucocytes, the cell suspensions obtained by forcing the organ through a nylon mesh were layered over a $51 \%$ Percoll (Sigma). After centrifugation at $400 \quad g$ for $30 \mathrm{~min}$ at $4^{\circ} \mathrm{C}$, the leucocytes fraction was removed from the Percoll-medium interface, washed 3 times, counted and adjusted to $510^{6}$ cells ml $^{-1}$. To get phagocytes, head-kidney cell suspensions, obtained as described above, were layered over a $34 / 51 \%$ Percoll density. After centrifugation at $400 \quad g$ for $30 \mathrm{~min}$ at $4^{\circ} \mathrm{C}$, the phagocyte-enriched interphase was collected and washed 3 times. Then, the cells were resuspended in culture medium, and dispensed into flat-bottomed 96-well plates. After $2 \mathrm{~h}$ at $20^{\circ} \mathrm{C}$, wells were washed with culture medium to remove non-adherent cells. The remaining phagocytes were detached from the plates by incubating for $1 \mathrm{~h}$ at $4^{\circ} \mathrm{C}$. Cell viability was examined with tryphan blue exclusion and evaluated to be greater than $95 \%$. The number of phagocytes were adjusted to $1 \quad 10^{6} \mathrm{cells} \mathrm{m}^{-1}$.

Chemiluminescence (CL) assay. The reactive oxygen species (ROS) produced by stimulated phagocytes was quantified using an automatic photoluminometer (Bio-Orbit 1251). Each test cuvette contained $0.7 \mathrm{ml}$ luminol (Sigma) made according to the method of Scott \& Klesius (1981), $0.4 \mathrm{ml}$ cell suspension, and $0.3 \mathrm{ml}$ zymosan (Sigma), which was added just prior to measurement. The measurements were made for $1 \mathrm{~h}$ and the assay was carried out in triplicate.

Direct priming effects of CpG ODN on respiratory burst activity of phagocytes. Head kidney phagocytes (1 $10^{6}$ cells ml-1), obtained as described above, were precultured for 6, 12 and $24 \mathrm{~h}$ with 0 (control), 1.25, 2.5, 5 and $10 \mu \mathrm{g} \mathrm{ml}^{-1}$ of $\mathrm{CpG}$ or $\mathrm{GpC}$ ODN at $20^{\circ} \mathrm{C}$. Cells were then washed twice with Hanks' balanced salt solution (HBSS, Sigma) to remove any residual ODN and analyzed for ROS production by CL as described above.

Priming effects of supernatants produced from leucocytes pulsed with $\mathrm{CpG}$ ODN on respiratory burst activity of phagocytes. Five $\mathrm{ml}$ of the leucocytes

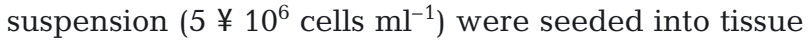
culture flasks $\left(25 \mathrm{~cm}^{2}\right)$, and were pulsed for $3 \mathrm{~h}$ at $20^{\circ} \mathrm{C}$ with $1.25,2.5,5.0$ and $10.0 \mu \mathrm{g} \mathrm{ml}^{-1}$ of $\mathrm{CpG}$ or GpC ODN. After that, the cells were gently washed 3 times with HBSS to remove any residual ODN, and cultured in L-15 medium for $48 \mathrm{~h}$. The supernatants were then harvested, centrifuged and stored at $-70^{\circ} \mathrm{C}$ until use. A supernatant collected from leucocytes that had not been pulsed with ODN was used as a control. The supernatants were diluted to a 1:8 or 
1:16 ratio with culture medium, and were added to the phagocytes monolayer in culture plates for 4,8 , 12 and $24 \mathrm{~h}$ at $20^{\circ} \mathrm{C}$. At each time point, the cells were washed twice with HBSS and analyzed for ROS production by CL.

In vivo stimulating effects of $\mathrm{CpG}$ ODN on respiratory burst of phagocytes. Acclimated juvenile olive flounder were divided into 5 groups, each containing 12 fish. CpG and GpC ODN were diluted with HBSS and injected intraperitoneally (i.p.) at a dose of 0.25 or $0.5 \mu \mathrm{fish}^{-1}$. Control fish received HBSS alone. Three fish of each group were sampled at 1, 3, 5 and $7 \mathrm{~d}$ after injection. Head kidney phagocytes were isolated as described above and analyzed for ROS production by CL.

Effects of CpG ODN on disease resistance. Acclimated juvenile olive flounder were divided into 5 groups, each containing 12 fish, and were treated i.p. with $\mathrm{CpG}$ or GpC ODN at a dose of 0.25 or $0.5 \mu \mathrm{g}$ fish $^{-1}$. Control fish received HBSS alone. Edwardsiella tarda FSW 910410, isolated from an episode of edwardsiellosis of olive flounder on a local farm in Korea, was obtained from the Laboratory of Fish Diseases Prevention, Pukyong National University. To enhance the virulence, the bacteria had been passaged in 5 naive olive flounders by i.p. injection. The bacterium was reisolated from the kidney of moribund fish $3 \mathrm{~d}$ later and cultured on trypticase soy agar (TSA; Sigma) plates supplemented with $1.5 \% \mathrm{NaCl}$ for $24 \mathrm{~h}$ at $27^{\circ} \mathrm{C}$. The bacterial cell suspension was adjusted to $1.3510^{6}$ colony forming units (cfu) $\mathrm{l}^{-1}$. Fish were challenged by immersion into $50 \mathrm{l}$ of the bacterial suspension for $30 \mathrm{~min}$ at $2 \mathrm{~d}$ post injection of either ODN or HBSS injection. Deaths were recorded over $15 \mathrm{~d}$. Dead fish were collected daily and necropsied. Kidney samples were streaked on TSA to confirm the presence of E. tarda.

Statistical analysis. Statistical significance was evaluated using Student's $t$-test, and $\mathrm{p}<0.05$ was considered statistically significant.

\section{RESULTS}

\section{Direct priming effects of $\mathrm{CpG}$ ODN on respiratory burst activity of phagocytes}

Head-kidney phagocytes precultured with CpG ODN for 6, 12 and $24 \mathrm{~h}$ showed significantly higher $\mathrm{CL}$ responses than phagocytes precultured with $\mathrm{GpC}$ ODN or culture medium alone (control) at all concentrations (Fig. 1). Phagocytes primed with $10 \mu \mathrm{g} \mathrm{ml}^{-1}$ of CpG ODN for $24 \mathrm{~h}$ showed significantly lower CL responses than those primed with lower concentrations of CpG ODN. Although phagocytes precultured with GpC ODN for $6 \mathrm{~h}$ at all concentrations and for 12 or $24 \mathrm{~h}$ at $1.25 \mu \mathrm{g} \mathrm{ml} \mathrm{m}^{-1}$ showed significantly higher $\mathrm{CL}$ responses than controls, the extent of CL enhancement was extremely low compared to $\mathrm{CpG}$ ODN.

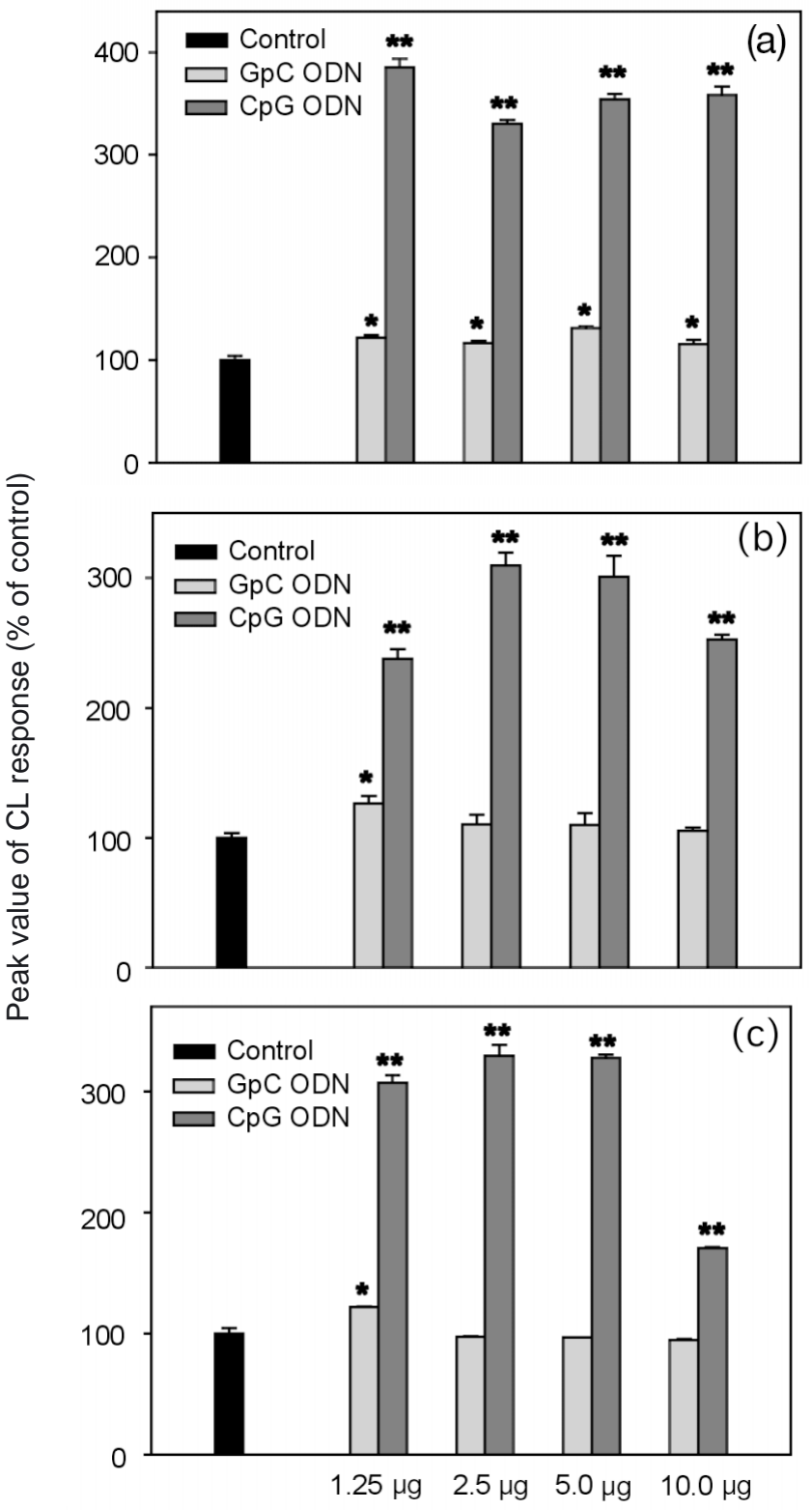

Fig. 1. Paralichthys olivaceus. Effects of synthetic oligodeoxynucleotides (ODN) on direct priming of respiratory burst activity of olive flounder head-kidney phagocytes. Phagocytes were precultured with various concentrations $\left(1.25,2.5,5.0\right.$ and $\left.10.0 \mu \mathrm{g} \mathrm{ml}^{-1}\right)$ of each ODN or medium alone (control) for (a) 6, (b) 12 and (c) $24 \mathrm{~h}$, then analyzed for reactive oxygen species (ROS)-production by chemiluminescence (CL) assay. Results are means of triplicate samples + SD. ${ }^{*}$ : Significantly different from control $_{i}{ }^{* *}$ : significantly different from control and GpC ODN; p < 0.05. CpG: cytidinephosphate-guanosine; GpC: guanosine-phosphate-cytidine 

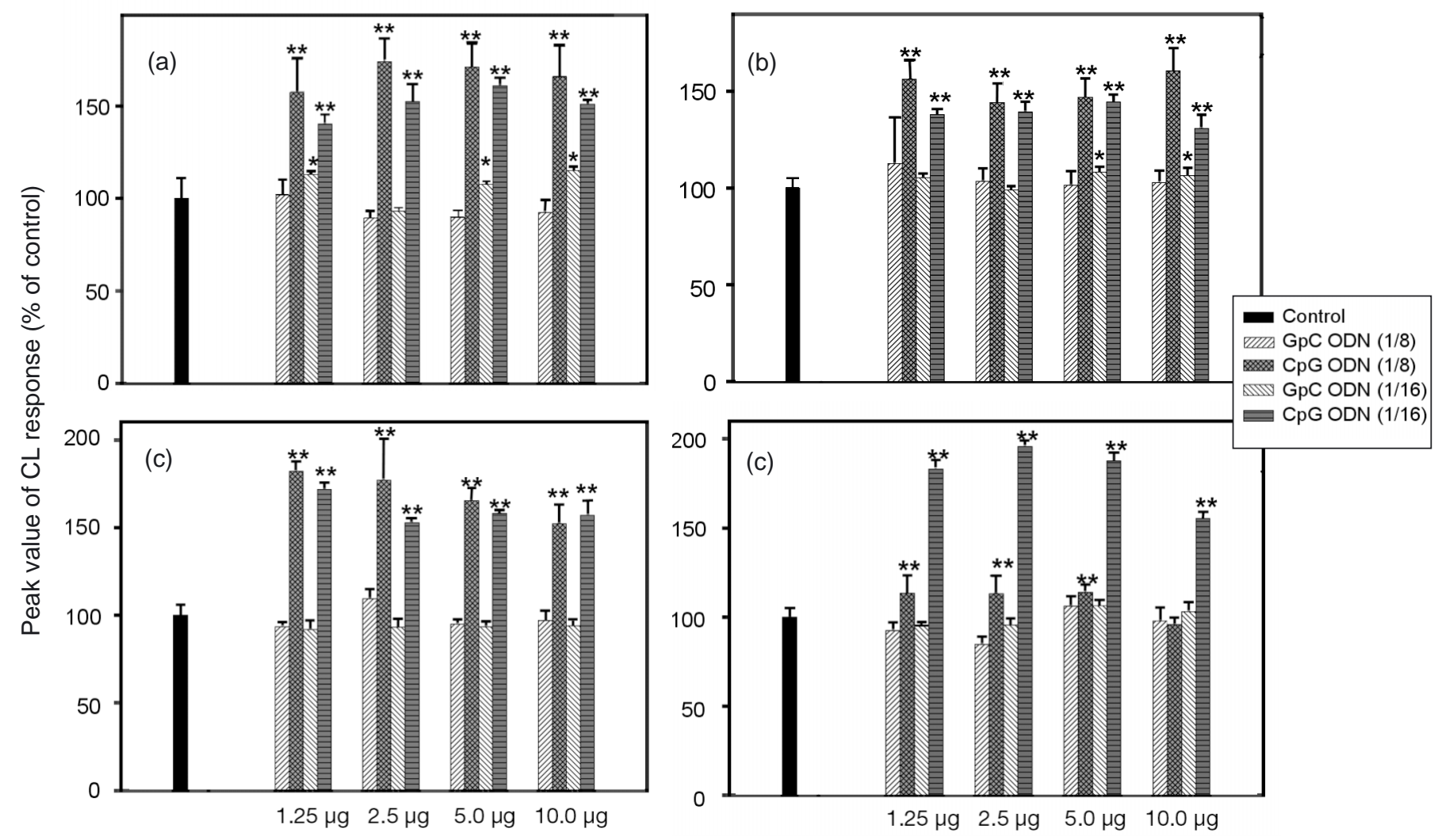

Fig. 2. Paralichthys olivaceus. Effects of supernatants (1:8 or 1:16 dilution) produced from leucocytes pre-primed with synthetic oligodeoxynucleotides (ODN) on the respiratory burst activity of olive flounder head-kidney phagocytes. Leucocytes were pulsed with various concentrations $\left(1.25,2.5,5.0\right.$ and $10.0 \mu \mathrm{g} \mathrm{ml}^{-1}$ ) of each ODN or medium alone (control) for $3 \mathrm{~h}$, and then washed gently. Supernatants were harvested after incubation of the washed leucocytes for $48 \mathrm{~h}$ at $20^{\circ} \mathrm{C}$. Target phagocytes were incubated with each diluted supernatant for (a) 4, (b) 8, (c) 12 and (d) $24 \mathrm{~h}$, and then analyzed for reactive oxygen species (ROS)-production by chemiluminescence (CL) assay. Results are mean of triplicate samples +SD. *: Significantly different from control; ${ }^{* *}$ : significantly different from control and GpC ODN; $\mathrm{p}<0.05$

\section{Priming effects of supernatants produced from leucocytes pulsed with $\mathrm{CpG}$ ODN on respiratory burst activity of phagocytes}

Supernatants produced from leucocytes pulsed with various concentrations of CpG ODN increased CL responses of head-kidney phagocytes significantly when compared to control, irrespective of dilution ratio, except for phagocytes primed by a supernatant produced by 1:8 dilution of $10 \mu \mathrm{g} \mathrm{ml}^{-1}$ for $24 \mathrm{~h}$ (Fig. 2). In contrast, supernatants produced by GpC ODN did not enhance significantly, or slightly, CL responses of phagocytes.

\section{In vivo stimulating effects of $\mathrm{CpG}$ ODN on respiratory burst of phagocytes}

Respiratory burst activities of head kidney phagocytes in the groups injected with either 0.25 or $0.5 \mu \mathrm{g}$ of
CpG ODN were significantly higher than those in the groups injected with GpC ODN or HBSS (control) at 3, 5 and $7 \mathrm{~d}$ after injection (Fig. 3). The group of fish injected with GpC ODN 1720 showed no significant differences with control in CL responses.

\section{Effects of CpG ODN on disease resistance}

The groups of fish injected with 0.25 or $0.5 \mu \mathrm{g}$ of $\mathrm{CpG}$ ODN showed higher survival rates (83.3\%) than groups treated with GpC ODN (33.3\%) and the control group (8.3\%) after challenge with Edwardsiella tarda (Fig. 4). All dead fish were positive for E. tarda.

\section{DISCUSSION}

In this study, olive flounder head-kidney phagocytes precultured with various concentrations of CpG ODN 


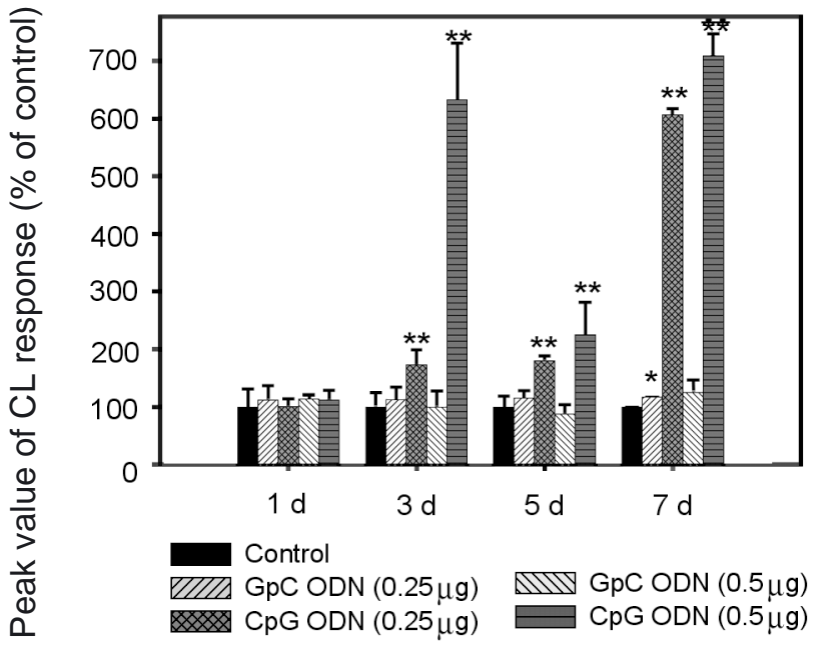

Fig. 3. Paralichthys olivaceus. Respiratory burst activity of head-kidney phagocytes of olive flounder injected intraperitoneally with 0.25 or $0.5 \mathrm{ml}$ of synthetic oligodeoxynucleotides (ODN) or HBSS alone (control). The respiratory burst activity was measured by chemiluminescent response (CL) and analyzed at 1, 3, 5 and $7 \mathrm{~d}$ after injection. Values are mean of triplicate samples + SD. ${ }^{*}$ : Significantly different from control $_{i}{ }^{* *}$ : significantly different from control and GpC ODN;

$$
\mathrm{p}<0.05
$$

for certain times $(6,12$ and 24 h) showed significantly higher CL responses than phagocytes precultured with GpC ODN or with medium alone. This result suggests that synthetic ODN containing the $\mathrm{CpG}$ motif can enhance respiratory burst activity of fish phagocytes, and this priming effect is not by nonspecific unmethylated DNA but by ODN containing the CpG motif. As the phagocytes were isolated by 2-step manipulation including Percoll gradient centrifugation and plate adhererence, phagocytes of fish are considered as effective target cells to respond to CpG ODN. In mammals, macrophages are involved in the production of Th1 cytokines as well as antigen processing/presentation, and thus play an important role in the response elicited by CpG DNA (Stacey et al. 1996, Sparwasser et al. $1997 a, b)$. In fish, Jørgensen et al. (2001a,b) demonstrated that the adherent cell population (macrophages were the dominant cell type) was the main source for CpG ODN-mediated expression of IFN-like cytokines and IL-1 . The CpG ODN 1668 used in this study has been shown to stimulate immune responses not only in mammals (Krieg et al. 1995, Lipford et al. 1997, Sparwasser et al. 1998, Yi \& Krieg 1998) but also in fish (Jørgensen et al. 2001a,b). Therefore, it can be considered that CpG ODN 1668 has an immunostimulating effect over a wide variety of vertebrates.

The present results demonstrate that olive flounder head-kidney leucocytes release a soluble phagocyte- activating factor(s) able to enhance the respiratory burst activity of target phagocytes. Supernatants produced from leucocytes, which were pulsed with $\mathrm{CpG}$ ODN for $3 \mathrm{~h}$ and subsequently cultured for $48 \mathrm{~h}$ with culture medium alone, induced significantly higher head-kidney phagocyte respiratory-burst activity than supernatants produced by GpC ODN or culture medium alone (control). Although there are several features that distinguish the CpG motifs' activation of immune cells from mitogen activation, the stimulating effect of CpG ODN in this study was similar to that of macrophage activating factor (MAF), which is produced by various mitogens, in that it primes the respiratory burst response of phagocytes after stimulation (Nagakawara et al. 1982, Graham \& Secombes 1988, 1990a,b).

In the present in vitro experiments, the highest concentration $\left(10 \mu \mathrm{g} \mathrm{ml}^{-1}\right)$ of CpG ODN showed relatively lower phagocyte-activating activities compared to lower concentrations. Klinman et al. (1996) reported that the production of cytokines, including IL-12 and IFN- from murine leucocytes, induced by CpG ODNs was higher at a concentration 0.10 to $0.33 \mu \mathrm{g} \mathrm{ml}^{-1}$ than that at $3.0 \mu \mathrm{g} \mathrm{ml}^{-1}$. Additionally, it has been demonstrated that MAF supernatants often show inhibitory effects on macrophage respiratory burst activity, possibly due to the presence of suppressive factors (Graham \& Secombes 1990a,b, Mulero \& Meseguer 1998).

In this study, groups of fish injected with a CpG ODN showed significantly higher respiratory burst activity of phagocytes. Similarly Tassakka \& Sakai (2002) reported that carp Cyprinus carpio injected intraperitoneally with CpG ODN showed significantly higher nitroblue tetrazolium (NBT) activity in kidney phagocytes.

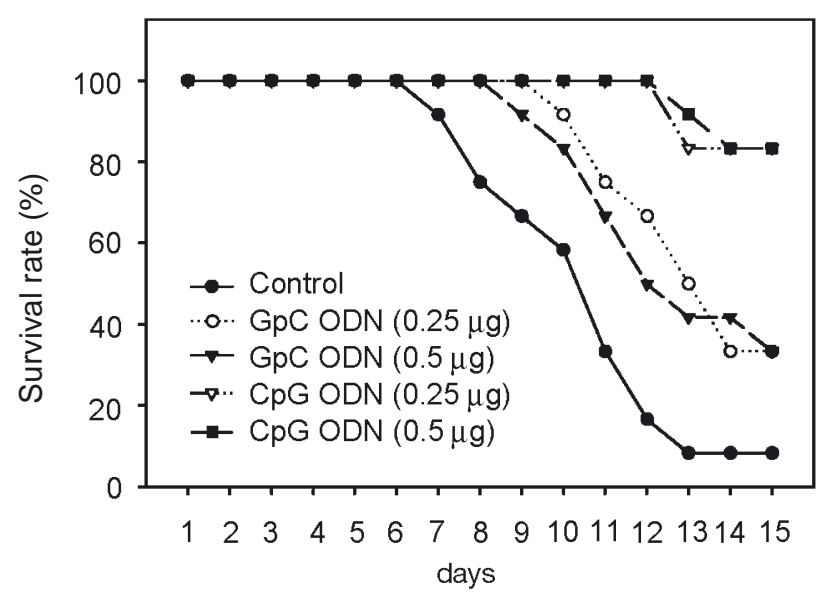

Fig. 4. Paralichthys olivaceus. Survival rate of olive flounder injected intraperitoneally with 0.25 or $0.5 \mathrm{ml}$ of synthetic oligodeoxynucleotides (ODN) or HBSS alone (control) after challenge with Edwardsiella tarda 
The rapid induction of an innate immune response is critical in controlling the early spread of intracellular pathogens. Although previous studies showed that CpG ODNs have significant in vitro biological activity, the in vivo significance of these effects has been unclear. The present results demonstrated that treatment of fish with DNA containing the CpG motif confers protection against lethal bacterial infection. Fish treated with a CpG ODN showed considerably higher survival rates than fish in control and GpC ODNinjected groups against Edwardsiella tarda challenge. Thus, the stimulation of innate protective immunity by host recognition of a synthetic ODN-containing $\mathrm{CpG}$ motif would contribute to the higher survival rate.

In conclusion, the present in vitro and in vivo experiments have demonstrated the ability of synthetic $\mathrm{CpG}$ ODN to increase phagocytes' respiratory burst activity and disease resistance in olive flounder Paralichthys olivaceus.

Acknowledgements. This work was supported by Grant No. R01-2000-000-00215-0 from the Basic Research Program of the Korea Science \& Engineering Foundation.

\section{LITERATURE CITED}

Ballas ZK, Rasmussen WL, Krieg AM (1996) Induction of NK activity in murine and human cells by CpG motifs in oligodeoxynucleotides and bacterial DNA. J Immunol 157: 1840-1845

Bird AP (1980) DNA methylation and the frequency of CpG in animal DNA. Nucl Acids Res 8:1499-1504

Bird AP (1987) CpG islands as gene markers in the vertebrate nucleus. Trends Genet 3:342-346

Chase JH, Hooker NA, Mildenstein KL, Krieg AM, Cowdery JS (1997) Bacterial DNA-induced NK cell IFN-gamma production is dependent on macrophage secretion of IL12. Clin Immunol Immunopathol 84:185-193

Graham S, Secombes CJ (1988) The production of a macrophage-activating factor from rainbow trout Salmo gairdneri leucocytes. Immunology 65:293-297

Graham S, Secombes CJ (1990a) Cellular requirements for lymphokine secretion by rainbow trout Salmo gairdneri leucocytes. Dev Comp Immunol 14:59-68

Graham S, Secombes CJ (1990b) Do fish lymphocytes secrete interferon- ? J Fish Biol 36:563-573

Hemmi H, Takeuchi O, Kawai T, Kaisho T and 7 others (2000) A toll-like receptor recognizes bacterial DNA. Nature 408: $740-745$

Jørgensen JB, Johansen A, Stenersen B, Sommer AI (2001a) CpG oligodeoxynucleotides and plasmid DNA stimulate Atlantic salmon (Salmo salar L.) leucocytes to produce supernatants with antiviral activity. Dev Comp Immunol 25:313-321

Jørgensen JB, Zou J, Johansen A, Secombes CJ (2001b) Immunostimulatory $\mathrm{CpG}$ oligodeoxynucleotides stimulate expression of IL-1 and interferon-like cytokines in rainbow trout macrophages via a chloroquine-sensitive mechanism. Fish Shellfish Immunol 11:673-682
Kanellos TS, Sylvester ID, Butler VL, Ambali AG, Partidos CD, Hamblin AS, Russel PH (1999) Mammalian granulocyte-macrophage colony-stimulating factor and some CpG motifs have an effect on the immunogenicity of DNA and subunit vaccines in fish. Immunology 96: 507-510

Klinman D, Yi AK, Beaucage SL, Conover J, Krieg AM (1996) CpG motifs expressed by bacterial DNA rapidly induce lymphocytes to secrete IL-6, IL-12 and INF. Proc Natl Acad Sci USA 93:2879-2883

Krieg AM, Hartmann G, Yi AK (2000) Mechanism of action of CpG DNA. Curr Top Microbiol Immunol 247:1-21

Krieg AM, Yi AK, Matson S, Waldschmidt TJ, Bishop GA, Teasdale R, Koretzky GA, Klinman DM (1995) CpG motifs in bacterial DNA trigger direct B-cell activation. Nature 374:546-49

Lipford GB, Bauer M, Blank C, Reiter R, Wagner H, Heeg K (1997) CpG-containing synthetic oligonucleotides promote $\mathrm{B}$ and cytotoxic $\mathrm{T}$ cell responses to protein antigen: a new class of vaccine adjuvants. Eur J Immunol 27: $2340-2344$

Meng Z, Shao J, Xiang L (2003) CpG oligodeoxynucleotides activate grass carp (Ctenopharyngodon idellus) macrophages. Dev Comp Immunol 27:313-321

Mulero V, Meseguer J (1998) Functional characterization of a macrophage-activating factor produced by leucocytes of gilthead seabream (Sparus aurata L.). Fish Shellfish Immunol 8:143-156

Nagakawara A, DeSaints NM, Nogueira N, Nathan CF (1982) Lymphokines enhance the capacity of human monocytes to secrete reactive oxygen intermediates. J Clin Invest 70 : 1042-1048

Oumouna M, Jaso-Friedmann L, Evans DL (2002) Activation of nonspecific cytotoxic cells (NCC) with synthetic oligodeoxynucleotides and bacterial genomic DNA: binding, specificity and identification of unique immunostimulatory motifs. Dev Comp Immunol 26:257-269

Scott AL, Klesius PH (1981) Chemiluminescence: a novel analysis of phagocytosis in fish. Dev Biol Standard 49: 243-254

Sparwasser T, Miethke T, Lipford G, Erdmann A, Hacker H, Heeg K, Wagner H (1997a) Macrophages sense phagogens via DNA motive induction of tumor necrosis factormediated shock. Eur J Immunol 27:1671-1679

Sparwasser T, Meithke T, Lipford G, Borschert K, Hicker H, Heeg K, Wagner H (1997b) Bacterial DNA causes septic shock. Nature 386:336-337

Sparwasser T, Koch ES, Vabulas RM, Heeg K, Lipford GB, Ellwart JW, Wagner H (1998) Bacterial DNA and immunostimulatory $\mathrm{CpG}$ trigger maturation and activation of murine dendritic cells. Eur J Immunol 28:2045-2054

Stacey KJ, Sweet MJ, Hume DA (1996) Macrophages ingest and are activated by bacterial DNA. J Immunol 157: $2116-2122$

Tassakka AR, Sakai M (2002) CpG oligodeoxynucleotides enhance the non-specific immune responses on carp, Cyprinus carpio. Aquaculture 209:1-10

Yamamoto S, Yamamoto T, Kataoka T, Kuramoto E, Yano O, Tokunaga $T$ (1992) Unique palindromic sequences in synthetic oligonucleotides are required to induce IFN and augment IFN-mediated natural killer activity. J Immunol 148:4072-4076

Yi AK, Krieg AM (1998) Rapid induction of mitogen-activated protein kinases by immune stimulatory CpG DNA. J Immunol 161:4493-4497 